\title{
The merger process between libraries of ML Sultan and Technikon Natal: reflections of a practitioner
}

\author{
Veena Jayaram \\ ML Sultan Campus Library, Durban Institute of Technology \\ jayaramv@dit.ac.za
}

Received: $8^{\text {th }}$ June 2002

Revised: $17^{\text {th }}$ October 2002

Education Minister Kader Asmal's plan to merge many of South Africa's tertiary institutions has given impetus to the merger of two of the country's oldest technikons, Technikon Natal and ML Sultan, both located in the city of Durban. This paper briefly sets out the scenario facing the institutions and the libraries, pre-merger as well as post-merger. It also provides a cursory glimpse of a few institutional challenges, some lessons learnt, and finally some recommendations.

The primary focus of this paper is not, however, to document the process involved in the merger of the libraries of these two institutions. This process was managed as a project, with a Project Manager being nominated from among the library staff. Various merger structures were put in place in order to facilitate participation by all staff. A Merger Management Committee (MMC) was established and departmental workgroups were formed consisting of relevant staff from both libraries. Representatives from these workgroups were elected to form a Sub-Committee that served as a liaison structure between staff and the MMC.

Regular meetings of all these groups took place as well as staff workshops and briefing meetings. A structure/model for the merged library was agreed to and estimates for database merger were calculated. Consensus was reached on many areas of function and service for the merged library, with common policies and procedures being formulated. Various committees are now working on space and HR issues.

Although this has been a voluntary merger, the newly formed Durban Institute of Technology (DIT) created out of the merger of ML Sultan and Technikon Natal institutions, has been experiencing some turbulent times in its short history. It is heartening to note that, from the libraries' point of view, the above has all been achieved in spite of the prevailing climate of unease regarding mounting merger costs and employment uncertainty among staff.

A time-line reflecting milestones in the merger process has been listed in the Appendix. It provides additional information and should be read in the context of the text.

\section{Introduction}

Who can blame them for their reluctance - when many executives in the corporate world have attempted to bring about changes in the organisation, and few have succeeded, and fewer still want to try again? (Hirschhorn, 2002). Despite the fact that the logistics can be enormously complex, change is an inescapable reality as even the higher education sector in South Africa braces itself for a rapid restructuring of its landscape. With the converging of institutional structures, departments and services, libraries too, have had their part to play in getting staff to better understand, participate and manage the change themselves (McKnight, 2002).

Cabinet's approval of the Government's groundbreaking proposals marked a turning point in the history of higher education in South Africa. These proposals make provision for a system that is both equitable in its distribution of resources and opportunities, as well as one that is academically and financially productive so that it can more effectively meet the teaching, skills and research needs of our country (Asmal, 2002).

The overall aim of this paper is to provide information on the process followed by libraries prior to merger as well as after the official announcement of merger, to initiate and sustain interaction/dialogue between staff of libraries of both ML Sultan and Technikon Natal.

It will provide information, both from the library perspective as well as institutional, on some problems experienced, lessons learnt as well as give recommendations. As the first merger of its kind in South Africa, it was felt that sharing such information would be valuable, especially for other institutions poised to go this route, as it reflects on the processes followed.

This paper does not cover other areas such as perceptions or emotions of participants, nor does it cover any surveys of participants, or aspects of managing cultural change that come with any reengineering process.

Note: This article is written with a mixture of academic and conversational language to capture the prevailing tone and mood of the process at the time.

\section{Why the need for restructuring?}

In South Africa, the agenda for the restructuring of higher education is a political one, underpinned by the necessity for transformation. Recommendations of the National Working Group Report For Mergers in Higher Education have 
changed the status quo at higher education institutions. According to Padayachee (2002) these government supported mergers have threatened higher education institutions' jealously guarded autonomy as well as privileges that went with it.

While the news has been 'largely welcomed' by certain institutions in KwaZulu Natal (Pillay, 200I), Padayachee (2002) observes that while the objectives such as transformation, academic excellence, economies of scale, broadening access that emerge from the various policy documents are not contested by the majority of institutions, the lack of process guidelines and resources to achieve these ends, have exacerbated an already volatile environment.

\section{The Institutions - pre-merger}

The pre-merger scenario is that ML Sultan Technikon and Technikon Natal existed as two separate entities within a few metres of each other, separated physically by only a fence. Each institution had, up until merger, functioned independently of the other with departments and sections being governed by their own Councils and structures.

\section{The scenario facing libraries - pre-merger}

With regard to the libraries, at the end of 1997, the Joint Council of the two institutions commissioned Price Waterhouse Coopers, who in turn commissioned Prof. Heather Edwards and Ms Hannie Sanders to carry out preliminary investigations into the feasibility of a merger. They were tasked to conduct an audit of existing library infrastructure and offer recommendations in the event of merger of both the institutions.

Once the team had made its recommendations, there was a long period of inactivity on this front; then came the restructuring announcement of the Minister of Education.

Prior to the Edwards/Sanders visit little attempt was made by either library to communicate or interact with each other. The Edwards/Sanders study revealed that while there were many similarities between the two libraries, there were many areas of differences. Differences related to physical space, structure of library buildings, infrastructure, resources (especially human resources) available, management styles and organisational culture. Systems of operation were considered to be consultative and participatory, on the one hand, to autocratic, on the other. Similarities in the main consisted of the range of services that were offered, the types of clientele served, record-keeping and reporting structures.

With I April 2002 being set as the date when merger of ML Sultan and Technikon Natal would become effective, the library departments of both institutions i.e. the BM Patel Memorial Library and the Alan Pittendrigh Library respectively, realised that there was no turning back - talks had to begin in earnest. Thus, in September of 200I, initial meetings took place between the management and a few key staff of the two libraries to plan around forthcoming developments and map out a way for their joint future.

\section{DIT is born!}

Now on ... now off! This was the scenario characterising the merger of the two institutions for a number of years until the new institution came into being on I April 2002. The Interim Council was then empowered with the authority to govern the new institution for the first six months, within a maximum period of a year; this Council would give way to a full Council after this period.

The Durban Institute of Technology thus emerged out of one of the first voluntary mergers, that of ML Sultan Technikon and Natal Technikon. This merger was driven by some of the national imperatives, but more specifically the need to dismantle barriers of separate education as were entrenched by apartheid.

\section{The merger process followed by the DIT libraries}

With minimal guidance from an institutional point of view, a key decision taken by the management of both libraries, was to handle the process of merger as a project: with a definite beginning and a definite end. The author, who was responsible for suggesting this, was nominated from amongst library staff to oversee and manage the project. The only guidelines available were those that the Project Manager thought were appropriate. Ground rules were set based on the following principles: transparency, openness, fairness, participation by all levels and by as many staff, striving towards best practice in as many areas as possible.

One of the very first steps that had to take place was the identification of stakeholders whose involvement in the process would be critical. These included:

- Library staff

- Library management

- Executive management

- Students

- Strategic alliance partnership with Mangosuthu Technikon Library

- Donors, suppliers, general public. 
The next step was to present an overview of the process to all library staff and Executive Management. In order to ensure buy-in and ownership of the process by all staff, which is vital in any process of change, the following structures were set up:

- Workgroups comprising all staff of similar sections within the libraries

- A Sub-committee consisting of a representative from each of the workgroups

- A Merger Management Committee (MMC) which included the two Library Directors, Deputy, Acting Deputies, Project Coordinators, and the Project Manager. The Coordinators were nominated from each library to assist the Project Manager and liaise with representatives from all the workgroups in order to facilitate communication at each library.

\section{Schedule of briefing meetings}

In order to inform all stakeholders of the way the library merger process was going to be handled, the Project Manager scheduled a series of separate briefing meetings as follows:

- With MMC

- With each of the workgroups

- With Executive Management, i.e. the Deputy Vice-Chancellor (Academic), also known as the 'sponsor'.

Initially, the format of these meetings was in two parts:

- Firstly, to unpack the process that was going to be followed, to keep staff informed of happenings, obtain feedback and to ensure three-way communication (up, down, sideways) amongst all staff.

- Secondly, to brief and equip staff with certain basic project management techniques that were to facilitate the process.

\section{Briefing meetings: Part One}

The Project Manager identified departments/sections within the library (e.g. Cataloguing sections from both libraries, Serials, Subject Librarians, etc.)

The purpose of merger was explained (efficiency, cost savings, resource sharing, taking into account imperatives of the National Plan)

The structure of committees, as well as reporting/communication lines, were established

Issues pertaining to departments/sections were identified e.g.

- Database integration

- Levels of cataloguing, choice of subject headings

- User education programmes

- Interlibrary tariffs

- Loan quotas for materials to be borrowed

- Reciprocal borrowing privileges

These were prioritized and categorized in terms of their importance (e.g. functions or services that could begin working together, things that needed some management or other intervention, or other matters that were long-term considerations

A schedule of MMC meetings was drawn up, together with dates of Sub-committee meetings for report back to; or feedback from representatives

At the same time, a schedule of meetings for each of the workgroups was drawn up with input from the groups; each group had to choose a set day/time of the week, to avoid coinciding with meeting times/days of other groups; once determined these were then diarised by all. Full participation and attendance was encouraged at all times

Report back and feedback sessions were factored in by the requirement that all workgroups had to submit a set of all minutes of their meetings to the Project Manager via the Coordinators

By meeting with representatives of workgroups who formed the Sub-committee opportunity was provided for MMC as well as members from other workgroups to be updated with the progress of each team

Monitoring of progress was to be carried out regularly by the Project Manager with assistance from Coordinators even if it meant attending many or all of these meetings themselves

Provision was made for minutes and progress reports to be placed on the notice boards at each library so that those staff unable to attend the meetings for legitimate reasons, but who wished to comment or provide input to discussions, could do so by going through postings on the board and communicating with Coordinators

The aim of each workgroup was to achieve a standard set of policies and procedures, always working towards best practice; identify strengths and see how these could be used positively to generate standards across the merged institution

Each workgroup agreed on certain ground rules, e.g. attendance and participation; ownership and 'buy in'; communication skills: listening, healthy disagreement, openness and sharing; adhering to deadlines and time frames for meetings and submission of reports of their discussions/deliberations to all members of their workgroups as well as MMC (Jayaram, 200I). 


\section{Briefing meetings: Part Two}

In order to prepare them for the format for discussions, each member of staff in the workgroup was briefed in terms of the following:

- What is Project Management

- What are its principles?

- The scope of the project

- Setting of objectives

- Arranging of activities

- Budget and resource considerations.

The nature of change: here the Kubler-Ross model of transition brought about by change was explained. Kubler-Ross developed one of the first models dealing with emotional change as she worked with people who were dying (KublerRoss, 1997). She saw them move through stages of shock, anger, denial, and gradual acceptance. These, she realised, could be applicable in any situation of change

Working towards the business process map and establishing a master program; the change of scenario that needed to be effected was a situation of 'As is' to 'As it will be' (Jayaram, 200I).

\section{The first joint merger meeting/workshop}

With opportunities having been presented for workgroups from each library to meet with their counterparts, it was now felt that staff could progress towards a totally new combined service ethos, and leave behind old paradigms and mindsets. One of the first issues work-shopped among the joint staff were:

- Principles of a structure for the 'New library service'

- Values that would underpin a common vision statement.

\section{Phase One / Priority I}

At this point, it needs to be stated that there were various institutional task teams being created, and the library task team was a part of the academic sector. Within that task team, the library operated in a fairly independent manner, with little institutional guidance in terms of what had to be worked on in the sequence of broader institutional events.

- The Project Manager together with the workgroups and MMC worked essentially independently with all staff participating in the planning of what the new structure should look like. Communication with the Deputy Vice-Chancellor (Academic), meant library staff going back to the drawing board, revisiting and reworking the library structure.

During discussions at various forums, it was acknowledged that the library should be viewed as the core focus upon which academic life hinges, hence a library model with centrally coordinated services to all DIT sites was established.

After a few meetings with the DVC, the MMC then worked towards submitting the following to the DVC, for submission to COT (the Committee of Thirteen - an institutional committee set up to manage merger issues until merger; after which the Interim Council would take its place):

- A document on the proposed structure for the new service, signed jointly by the Library Directors, Deputy Directors, Project Manager and Project Coordinators: a symbolic result showing the outcome of full consultation and agreement among staff, bearing the signature of all key management staff of both libraries.

- Estimates for database merger integration and related costs were also provided as this was an issue that was identified very early on as being a critical issue in merger.

\section{The second joint merger meeting / workshop}

Sufficient progress had been noted among the workgroups, and there was a strong sense that a shift had been made to new beginnings. A second joint workshop was scheduled just before the year-end vacation for a review to take place, as well as to plan for the forthcoming year. Some examples of discussions of the day were as follows:

- Reports from each workgroup : here each had to state areas where consensus had been reached, areas where it was not reached, and matters carried over for management to consider

- Library Directors once again brought to the attention of staff issues on the transition curve, e.g. pendulum swings of uncertainty, denial, shock, moving forward, moving back

- Issues of "Appreciative enquiry" were shared, i.e. transforming the change process into a positive way of thinking!

- A conscious decision was made by staff to formally let go of past, and celebrate our new beginning. This was done in a symbolic way by getting all staff to participate in a fun exercise and create something new: FRUIT SALAD!

- The day, and with it the year ended on a festive note with music, dance, sketches and role-play by workgroups, and a lunch! 


\section{2: the year of merger}

After a long break and vacations having come and gone, it was time to get back to the drawing board! In order to renew energies and build the momentum of the merger process once again, it was time to pick up threads of past discussions and weave them into stronger fabric for the coming year. With implementation date for merger apporaching, workgroups and departments had to work towards interim structures that could be put in place to ensure continuity of service. To this end:

- The Library Directors met

- The Sub-committee met; they were asked to identify issues that could be merged immediately, others that could run parallel to each other, and those that were unique

- These were arranged into a template by MMC, and

- Presented back to Sub-committee with action steps and time lines suggested by MMC.

\section{Seeking further advice ...}

With curiosity mounting as to what the institutional picture looked like and to ensure that the library was keeping in tandem with developments at that level, it was decided to approach the team of consultants which the two institutions were using to manage the institutional merger at the highest level. In this regard:

- The Project Manager sought an appointment with the consultants mentioned above to obtain advice

- Much work still needed to be accomplished in a number of areas, among them, the obtaining of quotations on the integration of the database and other merger costs

- A joint meeting with one of these consultants, the Library Directors and Project Manager took place

- The outcome was duly reported back to the Sub-committee and workgroups

- The impression gained was that right from the top down, there was a state of flux, and that much uncertainty prevailed at the institutional level in terms of 'who was supposed to be doing what'

- What was indicated was that broader institutional plans were being looked at e.g. HR, budget IT, infrastructure, and physical space, and the library would need to be prepared along similar lines

At a broader level, institutions that were preparing to go into merger or partnerships with others were invited to a workshop organised by the DoE/EU Higher Education Libraries Programme. The workshop on 'Mergers and Strategic Alliances' was designed to prepare library directors for such an event.

\section{Phase Two / Priority 2}

Discussions with the consultants, coupled with the increasing pressure from staff to know exactly where they stood with regard to HR matters, MMC determined its next area of priority. In this regard:

- Work began on the HR Structure; staff were asked to give their input regarding staffing issues in their respective areas and Library Directors were concurrently putting together a conceptual draft HR structure, taking into account some of the broad principles agreed on at the first joint meeting, viz. a centralized core of the directorate and technical services, with a distribution of information and other services at the site libraries

- Library Management reiterated its commitment to placement of existing staff first and foremost

- Workgroups were to come up with recommendations of any new, expanded services and staffing requirements thereof.

However, the library now faced the challenge that having first worked on the library structure, it had to commence populating the model: a process still underway.

\section{Interim measures in place ...}

With the April deadline for merger fast approaching, interim measures in terms of student and staff borrowing privileges and loan quotas were put into place so at to ensure that both main libraries would have uniform practices. Reciprocal borrowing privileges were arranged for students and staff of both institutions.

Many other crucial areas of user services have been and still are being worked on; these will be subject to approval by the Joint Interim Library Committee as well as Senex, a sub-body of Senate. Some measures have been implemented, as from the second semester of this year; others will follow next year.

Some examples of interim common Circulation policies that have been worked on are:

- Common library rules and regulations

- The instituting of fines at the library at ML Sultan has been adopted, as well as common charges for all DIT libraries (which presently include BM Patel Memorial Library [ML Sultan campus], Alan Pittendrigh [Steve Biko campus, formerly Technikon Natal], Riverside, Gamalakhe, Indumiso, Richards Bay, City and Brickfield)

- Photocopying charges have been standardised

- Interlibrary loans tariffs have been standardised; a courier service between certain site libraries is in place, with a more sophisticated system being proposed as developments progress. 


\section{Post merger: a few institutional challenges ...}

After I April 2002, processes institution-wide began to change. Meetings between Library Management task teams and the then Deputy Vice-Chancellor (Academic), had dissolved; reporting lines between Executive Management and the library had for a while become somewhat blurred. A new DVC (Academic) had been appointed in the interim, to oversee the institutional merger process, including that of the library.

In the meanwhile, the financial debt crisis of the former Technikon Natal began to exacerbate the deep sense of insecurity about merger issues that staff at the DIT libraries, and indeed staff at both institutions, had begun to feel. Thus, with the change in processes came other problems, e.g. managing and facilitating a merger plan so one could see the progress being made. In the case of DIT, there was no plan.

'Sultan staff cry foul' was the headline in the Natal Mercury (Naidu, 200I) as Technikon Natal was accused of showing bad faith dealings with salary hikes just before merger. Although this was a broader, institutional matter, at ground level, it had really shaken the faith of particularly ML staff, and had resulted in a negative climate prevailing throughout discussions. Much of the positive energy that went into discussions prior to this announcement seemed to have dissipated, and some fears of dealing with the unknown, had returned.

Key dependencies had not been worked out. HR issues remain a source of serious concern for staff at DIT libraries. Although staff have moved into the new institution (in terms of the labour laws) with the same terms and conditions of service that they enjoyed at their former institutions, subsequent changes in employment conditions, and fears over job losses are an inescapable reality for DIT (Bisetty, 2000)!

As these two tertiary institutions reposition themselves, many serious questions remain unanswered, for example, where will the money come from to make up the huge deficit (Naidu, 2002)? Further issues such as the equalization of salaries, cost of retrenchments, the offering of voluntary exit packages in the first phase instead of the option of redeployment, are yet other areas of concern.

From the libraries' point of view, immediately after the financial crisis was announced and there was threat that merger discussions would come to a halt, the Library Directors jointly issued a statement to all library staff expressing their intention, come what may, for the libraries to continue cooperating and working closely with each other.

The issue of the appointment of the Leader or Director of the library has been contentious. Until such time as HR matters are put in place, it does not seem that there will be any finality in this regard. The function is shared at present, however, at times, the tremendous uncertainty surrounding this area, filters into daily discussions and becomes a matter of real concern.

\section{Lessons learnt}

- One needs to bear in mind that the merger between the ML Sultan Technikon and Technikon Natal was a voluntary one; however, despite this, the merger experiences have generally been difficult. One can only imagine what would have happened had this been a forced merger. The situation at DIT gets quite volatile at times as employees threaten to embark on labour action because of Executive Management's failure to come up with a business plan (Mthembu, 2002).

- The absence, until now, of an institutional HR task team has had a direct bearing on some of the issues that have surfaced, viz. conditions of service, disparity of scales, lack of job descriptions, redeployment issues etc. Again, one can imagine the impact of all of these factors on productivity, as studies indicates that such stressors resulting from merger activity impact in a variety of ways on the individual, the institution, the leadership and on society at large (Padayachee, 2002).

- Although the combination of financial and human resources could result in a bigger, better, more thriving institution with a reduction in duplication, the decision to press ahead with merger nevertheless came as a shock to many staff who believed it would never happen (Garrow, 2002). Perhaps if staff were adequately prepared for the change, it might have been a different scenario. The Change Management office, although set up at DIT, seems to be working independently of the rest of the merger processes going on in the various sections.

- Financial considerations being the backdrop of the merger process rather than academia, have given a different slant to the entire merger. Due diligence should have been conducted and the information gleaned should have been cascaded to appropriate levels of staff in order for them to have arrived at a common base of understanding.

- With regard to the library, to a large extent, the library's approach to the merger process has been inward-looking, in a micro-cosmic kind of way rather than being outward focused and looking at structures and developments from the inside out.

- While it is acknowledged that communication is vital in any process of transition, balancing the pressure of work and the frequency of meetings has been a challenging time for staff. Garrow (2002) points out that these factors could lead to staff developing a dislike for attending meetings.

- To date the process at both library and institutional level is still unfolding, without any firm resolutions in many areas 
because of certain outstanding issues such as HR, space and finances.

\section{Conclusion}

- Even though the DIT merger was a voluntary one, it has gone through some turbulent times. For other institutions undergoing a similar exercise of merger, it would be extremely valuable, at the institutional level, for a merger office to be established right at the beginning. Work could begin with departments and task teams so that all key dependencies are understood. The office should only close once the merger has been accomplished. The Change Management office should work closely with this office and other departments on campus to facilitate the transition. These structures should be guided by a carefully thought out and well-defined business plan.

- One of the pitfalls in the pressure of merger is that it is easy to overlook or neglect the continuing pressures of normal day-day operations. It is recommended that this be very carefully factored into the schedule of merger related activities. A critical balance between people and productivity needs to be achieved.

- As the role of the Project Manager is a challenging one, perhaps such a person should be seconded to the position so that close workings with internal and external structures could be developed and maintained.

- People issues have to be managed right from the start and the human cost factor needs to be looked at very carefully, e.g. how the staff feel about the merger and what impact it has had on their work and their lives. While some research has commenced here, this could indeed provide the content for further follow up study.

- From conception of this first article from the DIT Library about merger, it has been recognised that further study will need to be done to capture, report and follow-up on related developments as this long-term process of merger continues to unfold.

\section{Appendix}

Time-line reflecting milestones in the merger process of the Libraries:

- Pre-200 I: Two independent libraries at two independent institutions of ML Sultan and Technikon Natal.

- 200 I: Minister announces restructuring plan for higher education.

- Sept 200I: Management and key staff of libraries begin preliminary talks.

- Sept 200 I: Project Manager nominated to handle merger of libraries.

- Oct 200I: Project Manager meets with Library Directors and Deputies to brief on process to be followed as well as form Merger Management Committee (MMC).

- Oct $200 \mathrm{I}$ : Project Manager Project meets with library sections in related groupings to form the Workgroups (consisted of all staff members of that section, e.g. Circulation, Cataloguing, Interlibrary Loans), to brief on process to be followed;

- Each workgroup had to nominate a representative from each library to form the Sub-committee.

- Oct 200 I: MMC and Project Manager nominate a Coordinator from each library to facilitate meetings and consolidate the coordinated process.

- Oct 200 I: Project Manager and Coordinators facilitate a joint workshop / second joint meeting of all staff of both libraries, which took place at Technikon Natal.

- Oct-Dec: Each Workgroup meets on their own, as well as send their representatives to Sub-committee meetings with MMC. MMC also meets to work on various operational and integration issues.

- Nov 200 I: Workshop by DoE/EU Higher Education Libraries Programme is held on Mergers and Strategic Alliances to which Library Directors and Project Manager get invited. Aim of the workshop was to assist participants from libraries whose institutions were becoming involved in partnerships, mergers, and alliances.

- Dec 200 I: Project Manager and Coordinators facilitate a joint workshop / second joint meeting of all staff of both libraries, which took place at ML Sultan: result-symbolic FRUIT SALAD!

- Jan 2002: Minister proclaims date of merger.

- Jan 2002: Meetings continue with MMC, Workgroups and Sub-committees; to work on and standardise interim measures (e.g. library rules, code of conduct, borrower privileges etc) leading up to merger deadline.

- Mar 2002: As at 3I March, two separate institutions exist, with separate structures, processes etc.

- April 2002: ML Sultan and Technikon Natal merge to become Durban Institute of Technology (DIT); campuses are know referred to as ML Sultan and Steve Biko Campus respectively.

- May 2002: Staff from both libraries participate in individual and group interviews share their fears, anxieties, experiences about the merger with a researcher at Roffey Park, involved in the project through DoE/EU Higher Education Libraries Programme. The researcher was to build a case study of the DIT merger, focussing in particular on the psychological aspects of merger. Material from Roffey Park research was incorporated in the 'Mergers and Strategic Alliances' workshop held in 200I.

- Jul-Aug 2002: Project Manager goes on Leadership training programme. Director of Steve Biko Campus takes on role of Director: Integration (Merger), together with Project Coordinators at ML and SB; Director of ML Campus takes on role of Director: Operations together with Deputies at ML and SB.

- Jul-Sep 2002: Workgroups begin work on policies, editorial committee formed at these meetings MMC works on HR 
structure - meets with all Workgroups to discuss.

- Sep 2002: Editorial committee starts work on editing policies.

- Sep-Oct 2002: Budget for 2003 prepared separately for the two libraries and then consolidated into one.

- To date: work goes on!

\section{References}

Asmal, K. 200I. National Plan for Higher Education. February. Website: http://education.pwv.gov.za

Asmal, K. 2002. Statement from Professor Kader Asmal on The Transformation and Reconstruction of the Higher Education System. Monday Edition [Newsletter - Publication of the Durban Institute of Technology], vol. I, no.4.

Asmal, K. 2002. The Transformation and Reconstruction of the Higher Education System. Sunday Times, 9 June.

Bisetty, Krisendra. 2000. Job fears over techs merger. The Daily News, 25 September.p.

Jayaram, Veena. 200I. ML Sultan - Technikon Natal library merger process/project management: briefing plan and notes. October.

Kubler-Ross, Elizabeth. 1997. On death and dying. New York: Macmillan.

Naidu, Buddy. 200I. Sultan staff cry foul. The Natal Mercury. 9 December. p.

Naidu, Buddy. 2002. Technikon debt row threatens to disrupt merger. The Sunday Times, I March, p.

Mthembu, Bongani. 2002. Work-to-rule threat at DIT. The Daily News, I October, p.

Pillay, Charmaine. 200I. Universities happy to restructure. The Natal Mercury, 8 March, p.

Hirschhorn, Larry. 2002. Campaigning for change. Harvard Business Review, July 2002, 98- 104.

Padayachee, Anshumali. 2002. Devising an action plan for Higher Education Mergers. [Article in press - Unpublished].

Padayachee, Anshumali. 2002. Mergers of Higher Education Institutions and the human cost factor. [Article in press Unpublished].

Garrow, Valerie. 2002. The Merger of ML Sultan and Natal Technikon Libraries: overview from interviews. $13-17$ May, [Unpublished].

McKnight, Sue. 2002. Managing cultural change: the challenge of merging library services, curriculum and academic professional development. Paper presented at 68th IFLA Conference, Scotland. August 2002. http://ifla.org 